\title{
ANÁLISE DOS PARÂMETROS MORFOMÉTRICOS DA SUB-BACIA HIDROGRÁFICA DO RIACHO CARAÚNA, EM QUIXERAMOBIM
} (CEARÁ)

Wagner José Rodrigues Lima ${ }^{1}$, Francílio de Amorim dos Santos ${ }^{2}$, Maria Lúcia Brito da $\mathrm{Cruz}^{3}$

(1 - Instituto Nacional de Colonização e Reforma Agrária, Graduado em Geografia, inspetorwagner@hotmail.com; 2 - Instituto Federal do Piauí / Campus Piripiri, Mestre em Geografia, francilio.amorim@ifpi.edu.br; 2 - UniversidadeEstadual do Ceará / Campusdo Itaperi, Doutora em Geografia, mlbcruz@gmail.com)

Resumo: O presente estudo propôs-se realizar a compartimentação da Sub-Bacia do riacho Caraúna (SBRC), analisar os parâmetros morfométrica, entender os processos erosivos e identificar as áreas potencialmente suscetíveis a eventos erosivos intensos. A SubBaciaestudada está localizada em Quixeramobim, estado do Ceará, possui uma área de 119 $\mathrm{km}^{2}$, que representa $3,6 \%$ da área do referido município. A SBRC integra a Bacia Hidrográfica de planejamento do rio Banabuiú. Utilizou-se imagem da Missão SRTM para delimitação e extração da rede de drenagem do objeto estudado. A proposta de compartimentação baseou-se em parâmetros como a densidade da rede de drenagem, densidade de riachos, linha divisora de águas e hipsometria. Os procedimentos técnicos foram realizados no Sistema de Informação Geográfica (SIG) Quantum GIS (QIGIS), versão 10.4 Essen. Desse modo, a análise das características geométricas, da rede de drenagem e do relevo da MBRC, assim como sua compartimentação em alto, médio e baixo curso permitiuverificar que: (a) as áreas mais vulneráveis aos processos erosivos e com maiores declividades encontram-se no alto curso da Sub-Bacia; e (b) que tem forma alongada e que é pouco suscetível a eventos de inundações e enchentes.

Palavras-chave: Parâmetros Geométricos. SRTM. Hidrografia. Geoprocessamento.

\section{ANALYSIS OF PARAMETERS MORPHOMETRIC BASIN STREAM CARAÚNA, IN QUIXERAMOBIM (CEARÁ - BRAZIL)}

Artigo recebido para publicação em 28 de Julho de 2016

Artigo aprovado para publicação em 01 de Dezembro de 2017 
Abstract: This study aimed to carry out the partitioning of Sub-Basin Caraúna stream (SBRC), analyze the morphometric parameters, understand the erosive processes and identify potentially susceptible areas to intense erosive events. The studied Sub-Basin is located in Quixeramobim, state of Ceará, has an area of $119 \mathrm{~km}^{2}$, which represents $3.6 \%$ of the area of said municipality. The SBRC is part of the river basin planning River Banabuiú. We used image SRTM Mission delineation and extraction of the object studied drainage network. The proposed subdivision was based on parameters such as the density of the drainage network, density streams, dividing line of waters and hypsometry. While the technical procedures were performed in the Geographic Information System (GIS) QuantumGIS (QGIS), version 10.4 Essen. Thus, the analysis of the geometric characteristics of the drainage network and relief MBRC, as well as its subdivision into high, medium and low course has shown that: (a) the area's most vulnerable to erosive processes and higher slopes are found on the upper course of the sub-basin; and (b) has elongated shape and is little susceptible to flooding and flood events.

Keywords:HydrographicBasin.Morphometry. CaraúnaStream.Hydrography.

\section{ANÁlisis DE LOS PARÁMETROS MORFOMÉTRICOS DE LA SUB-BACIA HIDROGRÁFICA DEL RIACHO CARAÚNA, EN QUIXERAMOBIM (CEARÁ)}

Resumen: El presente estudio se propuso realizar la compartimentación de la cuenca del riachuelo Caraúna (SBRC), analizar los parámetros morfométricos, entender los procesos erosivos e identificar las áreas potencialmente susceptibles a eventos erosivos intensos. La Subcuenca estudiada está ubicada en Quixeramobim, estado de Ceará, posee un área de 119 $\mathrm{km}^{2}$, que representa el 3,6\% del área de dicho municipio. La SBRC integra la Cuenca Hidrográfica de planificación del río Banabuiú. Se utilizó imagen de la Misión SRTM para delimitación y extracción de la red de drenaje del objeto estudiado. La propuesta de compartimentación se basó en parámetros como la densidad de la red de drenaje, densidad de arroyos, línea divisoria de aguas y hipsometría. Mientras que los procedimientos técnicos se realizaron en el Sistema de Información Geográfica (SIG) Quantum GIS (QGIS), versión 10.4 - Essen. De este modo, el análisis de las características geométricas, de la red de drenaje y del relieve de la MBRC, así como su compartimentación en alto, medio y bajo curso, permitió verificar que: (a) las áreas más vulnerables a los procesos erosivos y con mayores declividades, si en el alto curso de la cuenca; y (b) que tiene forma alargada y que es poco susceptible a eventos de inundaciones e inundaciones. 


\section{GEOAMBIENTE ON-LINE \\ Revista Eletrônica do Curso de Geografia - UFG/REJ \\ Graduação e Pós-Graduação em Geografia \\ http://revistas.ufg.br/index.php/geoambiente/index \\ Apoio: PRPG/PROAPUPEC \\ Jataí-GO | n 29 | Jul-Dez/2017}

气GEO

亡̈AMBIENTE

ISSN 1679-9860

Palabras-clave: Parámetros Geométricos. SRTM. Hidrografía. Geoprocesamiento.

\section{INTRODUÇÃO}

A água é fundamental para a vida no planeta. Desse modo, o Nordeste do Brasil (NEB), que se configura como a região com os menores e irregulares índices pluviométricos do Brasil, representa uma região em que a preocupação em estudar-se a superfície terrestre ocupada pela água doce é preponderante. Um melhor planejamento e uso racional dos recursos naturais nestas regiões é ainda mais significativo.

Identificar a localização e a quantificação dos corpos hídricos continentais, especialmente os riachos, torna-se impar para a ciência, visto que forma uma base sólida. Whitehead e Robinson (1993) confirmam que há carência de estudos cartográficos sobre a drenagem que objetivam a análise das dinâmicas e dos processos controladores do comportamento da água juntamente com os impactos das mudanças do uso da superfície do solo sobre a qualidade e quantidade de água.

A grande dimensão territorial do país e as dificuldades de acesso a áreas inóspitas são fatores preponderantes para o conhecimento limitado da rede de drenagem. Assim, o geoprocessamento e o sensoriamento remoto torna-se uma ferramenta fundamental para a identificação e caracterização da drenagem. Nessa perspectiva, Alves Sobrinho. (2010) utilizou um processo para delimitação automática de bacias hidrográficas e constatou que esse procedimento apresentou grande vantagem em relação ao custo e benefício proporcionado, com precisão compatível à metodologia baseada em cartas topográficas.

Deve-se destacar que a maior parte dos rios situados na região semiárida brasileira apresenta como característica marcante o caráter intermitência, pois permanecem secos a maior parte do ano e, por conseguinte, com baixo potencial de vazão. Nesse contexto, insirase o conceito de rede de drenagem que pode ser compreendida como o ente da Sub-Bacia Hidrográfica com os processos mais ativos na formação da paisagem terrestre. Ao passo que os valores dos parâmetros morfométricos obtidos via análises quantitativas, apontam as principais características areais, lineares e hipsométricas (CHRISTOFOLETTI, 1980).

Frente ao que foi apresentado, acima, o conhecimento da rede de drenagem torna-se fator estratégico para a gestão territorial no âmbito municipal, visto que pode subsidiar ações no meio físico-natural e social das comunidades residentes na Sub-Bacia.Nesse cenário, a presente pesquisa buscou realizar análise morfométrica, compreender os processos erosivos e 


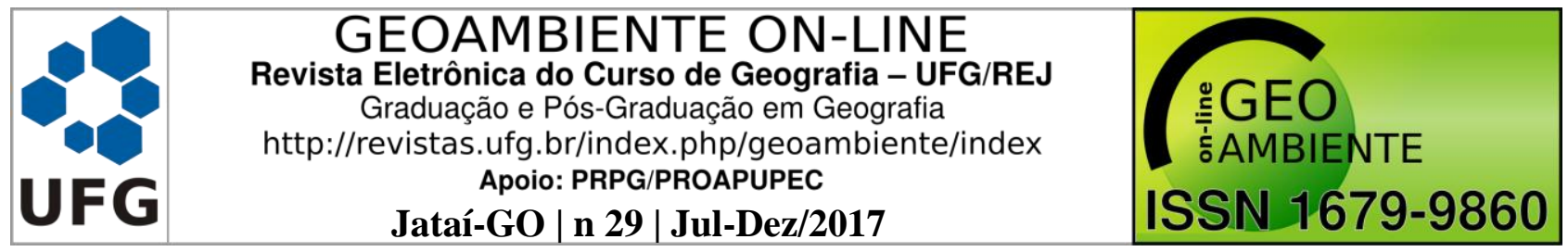

identificar as áreas potencialmente suscetíveis aos eventos erosivos intensos, da Sub-Bacia do riacho Caraúna, localizada em Quixeramobim, estado do Ceará.

\section{FUNDAMENTAÇÃO TEÓRICA}

De início cabe definir o conceito de bacia hidrográfica, que está relacionado com a declividade e a linha divisora d'água. Diga-se, ainda, que pode ser compreendida como uma área de caimento natural com drenagem convergente para um leito principal até o exutório. Nesse sentido, pode entender que

[...] bacia hidrográfica pode ser definido como o conjunto das áreas com declividade no sentido de determinada seção transversal de um curso de água, medidas as áreas em projeção horizontal. Pode-se também definir bacia hidrográfica como sendo uma área definida e fechada topograficamente num ponto do curso de água, de forma que toda a vazão afluente possa ser medida ou descarregada através desse ponto (VIESSMAN et al., 1972; GARCEZ e ALVAREZ, 1988).

Neste ponto de vista, a bacia hidrográfica coloca-se como unidade físico-territorial onde se desenvolve toda a dinâmica ambiental, essa ocorrendo com inter-relação entre os seus componentes físicos, socioeconômicos e biológicos.Ratificando este entendimento, Farias et al. (2015, p. 15) expõem que

\footnotetext{
As bacias hidrográficas destacam-se como unidades físico-territoriais que viabilizam as ações de planejamento e gestão ambiental em determinados espaços, priorizando o estabelecimento de propostas voltadas para a preservação dos recursos naturais, a satisfação das necessidades humanas e o desenvolvimento econômico embasados nos princípios da sustentabilidade. Nas regiões semiáridas as bacias hidrográficas de destacam como ferramentas que viabilizam a implementação de ações mitigadoras de convivência com a seca.
}

Pereira Neto (2015) ressalta que a bacia hidrográfica, atualmente, constitui uma unidade basilar para análise e planejamento ambiental, sendo o elemento sistêmico, englobando distintas áreas do conhecimento.No contexto da bacia hidrográfica o ente integrador é a rede de drenagem, sendo os cursos d'água os principais agentes modeladores da paisagem e formadores geomorfológicos na depressão sertaneja (ANTONELLI e THOMAZ, 2007). No entanto não se pode deixar de ter uma visão mais ampliada para as relações socioeconômicas e culturais.

Depreende-se, desta forma, que as margens da rede de drenagem, compostas pelas planícies fluviais são ambientes típicos de acumulação de sedimentos decorrentes da ação 


\begin{tabular}{|c|c|c|}
\hline & $\begin{array}{c}\text { GEOAMBIENTE ON-LINE } \\
\text { Revista Eletrônica do Curso de Geografia - UFG/REJ } \\
\text { Graduação e Pós-Graduação em Geografia } \\
\text { http://revistas.ufg.br/index.php/geoambiente/index } \\
\text { Apoio: PRPG/PROAPUPEC }\end{array}$ & $\begin{array}{l}\text { ¿AMBIENTE } \\
\text { SN 1679-986 }\end{array}$ \\
\hline & Jataí-GO | n 29 | Jul-L & \\
\hline
\end{tabular}

gravitacional e fluvial (SOUZA et al., 2009). Nessa perspectiva, Soares e Sousa (2012) asseveram que é por meio dos fatores morfométricos que se chega às principais particularidades de uma bacia hidrográfica. Desse modo, é essencial conhecer os parâmetros morfométricos, visto que possibilitam a verificação e análise areal, linear e hipsométrica das questões relacionadas com os processos biofísicos da Sub-Bacia.

O conhecimento dessas desses grupos de variáveis gera informações que constituem ponto de partida para o planejamento ambiental e avaliação de índices importantes para a prevenção de riscos ambientais. No presente estudo foram utilizados os seguintes parâmetros geométricos: Área, Perímetro, Fator Forma de Bacia (a razão entre a largura média da bacia e o comprimento do eixo da bacia), Índice de Circularidade e o Coeficiente de Compacidade (relação entre o perímetro da bacia e o perímetro de um círculo de mesma área que a bacia), conforme atestam Carvalho, Mello e Silva . (2007).

O grupo de variáveis que compreendem a rede de drenagem foram os seguintes: comprimento total dos cursos d'água, Densidade de Drenagem (relação entre o comprimento total dos cursos d'água de uma bacia e sua área), Densidade hidrográfica (número de canais existentes em cada quilômetro, Gradiente dos canais, Coeficiente de manutenção (área mínima necessária para a manutenção de um metro de canal de escoamento (TONELLO et. al., 2006; MIRANDA et al., 2011), ordem dos cursos d'água que constitui o grau de ramificação do sistema de drenagem da bacia, executado de acordo com a proposta metodológica de Strahler (1952).

Por sua vez, as particularidades do relevo foram identificadas por meio das variáveis: altitude mínima, altitude máxima, a altitude média,amplitude altimétrica máxima e, ainda, a declividade, que é expressa como a variação de altitude entre dois pontos do terreno, em relação à distância que os separa. Outro parâmetro importante é o Índice de Rugosidade, produto da amplitude altimétrica e da densidade de drenagem (SOARES e SOUSA, 2012).

Para Christofoletti (1980), a análise morfométrica de uma bacia hidrográfica pode ser dividida em quatro vertentes, quais sejam: 1 - hierarquização da rede de drenagem; 2 análise linear dos cursos d'água; 3 - análise areal da bacia, compreendendo os valores planimétricos e lineares; e 4 - análise hipsométrica.

A análise morfométrica baseada na geomorfologia da superfície terrestre e na rede hidrográfica é um recurso já utilizado por outros autores, como Soares e Souza (2012) com o artigo análise morfométrica da bacia hidrográfica do Rio Pequeno em São José dos Pinhais 


\begin{tabular}{|c|c|c|}
\hline U & $\begin{array}{c}\text { GEOAMBIENTE ON-LINE } \\
\text { Revista Eletrônica do Curso de Geografia - UFG/REJ } \\
\text { Graduação e Pós-Graduacão em Geografia } \\
\text { http://revistas.ufg.br/index.php/geoambiente/index } \\
\text { Apoio: PRPG/PROAPUPEC } \\
\text { Jataí-GO | n 29|Jul-Dez/2017 }\end{array}$ & $\begin{array}{l}\text { OIENTE } \\
1679-9860\end{array}$ \\
\hline
\end{tabular}

(PR); Araújo et. al., (2013) com o trabalho sobre o uso das geotecnologias para a caracterização morfométrica de bacia hidrográfica.

Soares e Sousa (2012), por sua vez, realizaram levantamento planialtimétrico e traçaram curvas de nível, obtendo as variáveis numéricas automaticamente por programa especializado em informações geográficas, sendo que para a compartimentação da bacia, foram utilizados critérios hidrográficos, hipsométricos e o perfil da bacia.

\section{PROCEDIMENTOS METODOLÓGICOS}

A Sub-Bacia hidrográfica do riacho Caraúna (SBRC) está localizada entre as coordenadas planas Norte 9404339 e Este 437971 e Norte 9424024 e Este 459005 da zona 24 Sul (Figura 1), do plano Universal Transverso de Mercator, com área aproximadamente 119 $\mathrm{km}^{2}$, compreendendo 3,6\% da área do município de Quixeramobim. A SBRC integra a Bacia Hidrográfica de planejamento do rio Banabuiú.

Figura 1: Localização geográfica da Sub-BaciaHidrográfica do riacho Caraúna (SBRC) e sua rede de drenagem.

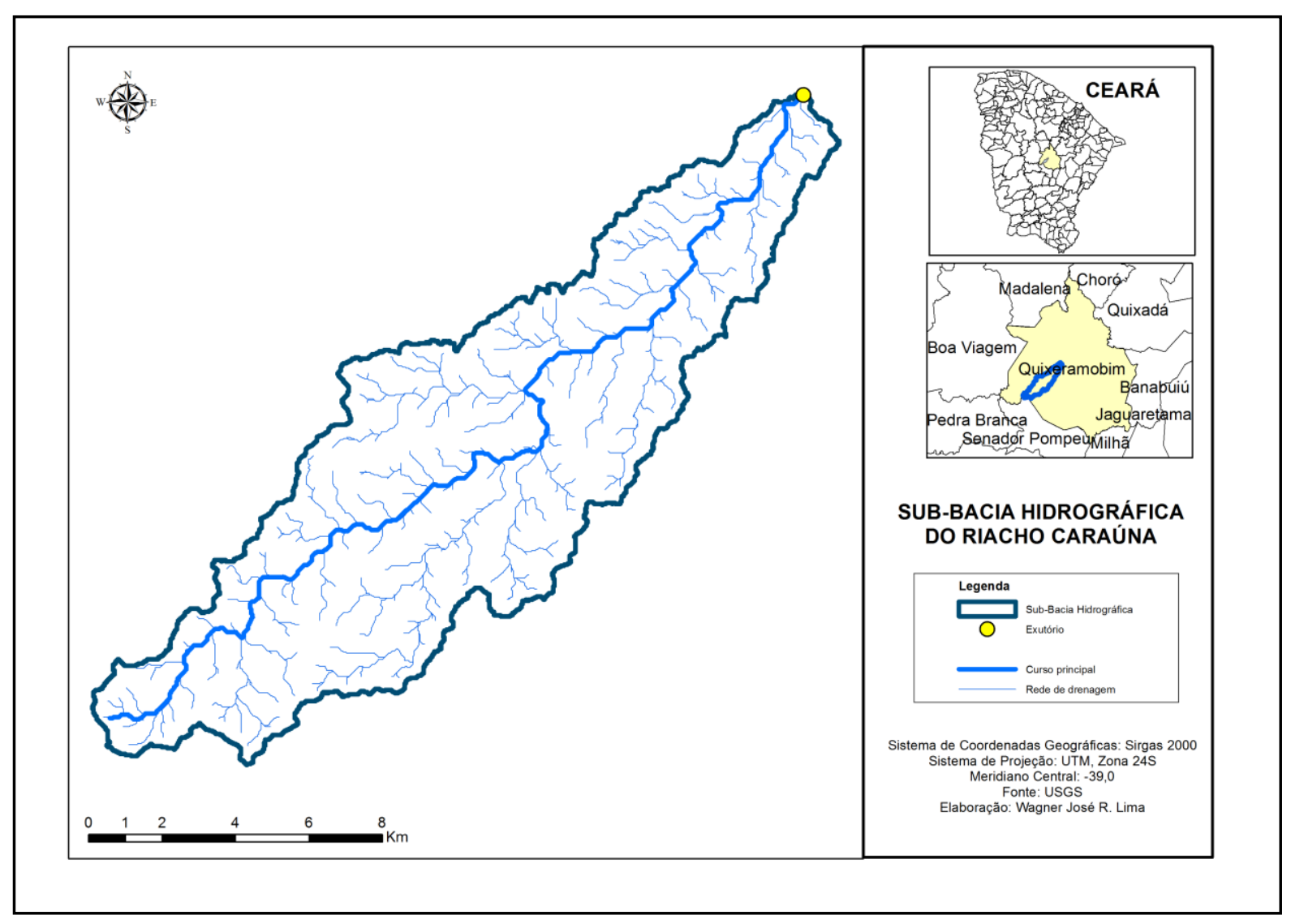




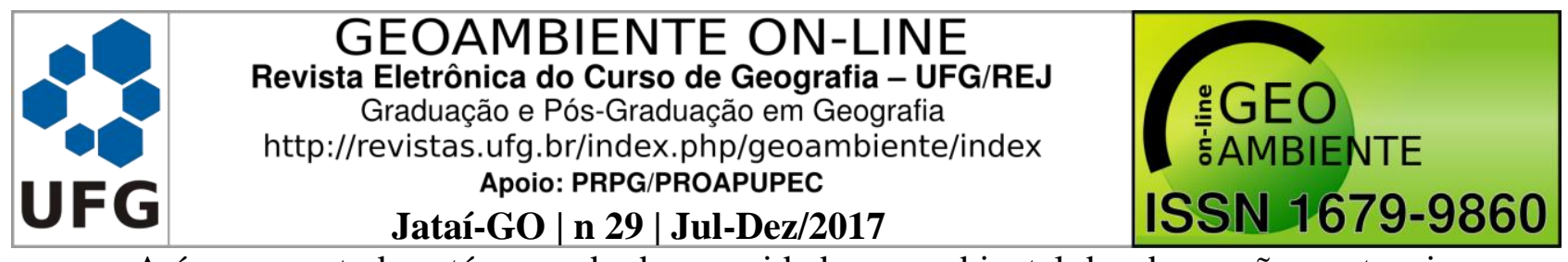

A área em estudo está enquadrada na unidade geoambiental das depressões sertanejas, as quais foram e estão submetidas às sucessivas fases dos processos erosivos (LIMA, CRISPIN e SOUZA, 2014). A delimitação do objeto em estudo deu-se por modelos matemáticos de análise espacial aplicados em SIG utilizando imagens da Missão SRTM, executado no ano 2000, e disponibilizado no site <http://earthexplorer.usgs.gov/> do USGS (2015).

Ressalta-se que todos os dados estão estruturados em quadrículas compatíveis com a articulação 1:250.000, com resolução espacial plana de 30 metros. A folha 05S_405ZN, foi escolhida por compreender a área da SBRC, objeto estudado na presente pesquisa. O Modelo Digital de Elevação (MDE) utilizado para extração da rede de drenagem precisou ser reprojetado para o Sistema de Coordenadas Planas UTM de acordo com a localização.

A partir da imagem de radar tratada e das técnicas computacionais, foram gerados os mapas da rede de drenagem, elevação, curvas de nível, delimitação, compartimentação e de declividade. Ressalta-se, ainda, que foram utilizados arquivos vetoriais disponibilizados pelo Instituto Brasileiro de Geografia e Estatística (IBGE) através do sítio eletrônico. Os procedimentos técnicos descritos para análise morfométrica foram realizados no Sistema de Informação Geográfica (SIG) Quantum GIS (QIGIS), versão 10.4 - Essen.

A análise morfométrica da Sub-Bacia foi calculada com base nas características geométricas, rede de drenagem e relevo, conforme foi conceituado anteriormente. As variáveis consideradas nesse estudo estão dispostas no Quadro 1.

\section{ANÁLISE E DISCUSSÃO DOS DADOS}

A Sub-Bacia do riacho Caraúna (SBRC)compreende 3,6\% da área do município de Quixeramobim e integra a Bacia Hidrográfica de planejamento do rio Banabuiú. Por meio dos dados SRTM foi possível identificar que a SBRC apresenta uma área drenada de $119,25 \mathrm{~km}^{2}$ pelo conjunto da rede fluvial e perímetro de $93,54 \mathrm{~km}$, com rede de drenagem bastante ramificada com hierarquia fluvial de $4^{\mathrm{a}}$ ordem (Quadro 2). 
Quadro 1: Parâmetros morfométricos analisados da Sub-Bacia do riacho Caraúna (SBRC).

\begin{tabular}{|c|c|c|c|c|}
\hline & Parâmetro & Equação & Definição & Unidade \\
\hline \multirow{4}{*}{ 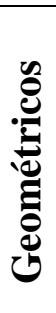 } & Área $(A)$ & $A$ & $A=$ área da bacia em $\mathrm{km}^{2}$. & $\mathrm{km}^{2}$ \\
\hline & Perímetro $(P)$ & $P$ & $P=$ perímetro da bacia em $\mathrm{km}^{2}$. & $\mathrm{km}^{2}$ \\
\hline & $\begin{array}{l}\text { Fator forma da bacia } \\
\qquad(F f)\end{array}$ & $F f=\frac{A}{L^{2}}$ & $\begin{array}{c}A=\text { área da bacia em } \mathrm{km}^{2} \\
L=\text { comprimento do eixo }(\mathrm{km}) .\end{array}$ & - \\
\hline & $\begin{array}{c}\text { Coeficiente de } \\
\text { compacidade }(K c)\end{array}$ & $K c=\frac{0,28 p}{\sqrt{A}}$ & $\begin{array}{c}A=\text { área da bacia em } \mathrm{km}^{2} ; \\
P=\text { perímetro da bacia em } \mathrm{km}^{2} .\end{array}$ & - \\
\hline \multirow{7}{*}{ 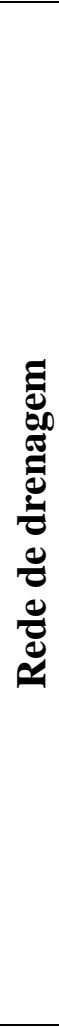 } & $\begin{array}{l}\text { Ordem dos cursos } \\
\text { d'água }\end{array}$ & & - & - \\
\hline & $\begin{array}{l}\text { Comprimento total dos } \\
\text { cursos d'água ( } L \text { total) }\end{array}$ & $L$ & $\begin{array}{c}L=\text { comprimento total dos } \\
\text { cursos d'água }(L \text { total em } \mathrm{km})\end{array}$ & $\mathrm{km}$ \\
\hline & $\begin{array}{l}\text { Comprimento médio } \\
\text { dos riachos }(L m)\end{array}$ & $L m=\frac{L u}{N u}$ & $\begin{array}{c}L u=\text { extensão total dos rios } \\
(\mathrm{km}) ; \mathrm{Nu}=\text { número total de rios } \\
\text { (quantidade). }\end{array}$ & $\mathrm{km}$ \\
\hline & $\begin{array}{l}\text { Gradiente dos canais } \\
\qquad(G)\end{array}$ & $G=\left(H-\frac{h}{L}\right) \cdot 100$ & $\begin{array}{c}H=\text { altitude da nascente }(\mathrm{m}) ; h \\
=\text { altitude da foz }(\mathrm{m}) ; \mathrm{L}= \\
\text { Comprimento do rio principal } \\
(\mathrm{km}) .\end{array}$ & $\%$ \\
\hline & $\begin{array}{l}\text { Índice de sinuosidade } \\
\qquad(I s)\end{array}$ & $I s=\frac{L}{L t}$ & $\begin{array}{c}L=\text { comprimento do rio } \\
\text { principal }(\mathrm{km}) ; \mathrm{Lt}= \\
\text { comprimento do eixo da bacia } \\
(\mathrm{km}) .\end{array}$ & - \\
\hline & $\begin{array}{l}\text { Densidade de } \\
\text { drenagem }(D d)\end{array}$ & $D d=\frac{L_{t}}{A}$ & $\begin{array}{c}\text { Lt = comprimento total dos } \\
\text { canais em } \mathrm{km} ; A=\text { área da } \\
\text { bacia em } \mathrm{km}^{2} .\end{array}$ & $\mathrm{km} / \mathrm{km}^{2}$ \\
\hline & Densidade de rios $(D r)$ & $D h=\frac{n}{A}$ & $\begin{array}{c}n=\text { número de canais; } \\
A=\text { área total da bacia em } \mathrm{km}^{2} .\end{array}$ & $\begin{array}{l}\text { canais/k } \\
\mathrm{m}^{2}\end{array}$ \\
\hline \multirow{7}{*}{$\frac{2}{2}$} & Altitude mínima & $H_{\min }$ & $H_{\min }=$ altitude mínima & $\mathrm{m}$ \\
\hline & Altitude máxima & $H_{\max }$ & $H_{\max }=$ altitude máxima & $\mathrm{m}$ \\
\hline & $\begin{array}{l}\text { Amplitude altimétrica } \\
\text { máxima }\end{array}$ & $H_{\max }=H . h$ & $\begin{array}{c}H=\text { altitude do ponto mais alto } \\
\text { situado em qualquer lugar da } \\
\text { divisória topográfica; } \\
\mathrm{h}=\text { altitude da foz. }\end{array}$ & $\mathrm{m}$ \\
\hline & Declividade mínima & $D_{\min }$ & $D_{\min }=$ altitude mínima & $\%$ \\
\hline & Declividade máxima & $D_{\max }$ & $D_{\max }=$ altitude máxima & $\%$ \\
\hline & Declividade média & $D m=\frac{x_{1}+\cdots+x_{n}}{n}$ & $\begin{array}{c}x=\text { valores de delividades } \\
n=\text { número de observações }\end{array}$ & $\%$ \\
\hline & $\begin{array}{l}\text { Índice de rugosidade } \\
\qquad \text { (Ir) }\end{array}$ & $I r=H \times D d$ & $\begin{array}{c}H=\text { amplitude altimétrica em } \\
\mathrm{m} ; \\
\text { Dd = densidade de drenagem } \\
\mathrm{em} \mathrm{km} / \mathrm{km}^{2} .\end{array}$ & - \\
\hline
\end{tabular}


Quadro 2: Características morfométricas analisadas da Sub-Bacia Hidrográfica do riacho Caraúna (SBRC).

\begin{tabular}{|c|c|c|c|}
\hline Parâmetro & Valores & Parâmetro & Valores \\
\hline Ordem da Sub-Bacia & $4^{\text {a }}$ & Altitude mínima & 202 metros \\
\hline Área da Sub-Bacia & $119,2527 \mathrm{~km}^{2}$ & Altitude média & 269,89 metros \\
\hline Perímetro & $93,54 \mathrm{~km}$ & Altitude Máxima & 464 metros \\
\hline Coeficiente de Compacidade & 2,39 & Declividade Mínima & $0 \%$ \\
\hline Fator de Forma & 0,1092 & Declividade média & $5,44 \%$ \\
\hline Densidade de rios & $1,6016 \mathrm{~km}^{2}$ & Declividade Máxima & $50,49 \%$ \\
\hline Densidade de drenagem & $1,0376 \mathrm{~km} / \mathrm{km}^{2}$ & Índice de sinuosidade & 0,7778 \\
\hline $\begin{array}{c}\text { Comprimento do canal } \\
\text { principal }\end{array}$ & $33,04 \mathrm{~km}$ & $\begin{array}{c}\text { Comprimento total da } \\
\text { drenagem }\end{array}$ & $222,43 \mathrm{~km}$ \\
\hline
\end{tabular}

Fonte: Elaborado pelos autores (2017).

Em relação ao fator de forma e o coeficiente de compacidade da Sub-bacia foram identificados os valores de 0,1092 e 2,39, respectivamente. Observa-se que os parâmetros distanciam-se da unidade (1), indicando assim, que a SBRC não apresenta a forma de uma circunferência e, por conseguinte, possui baixa susceptibilidade a processos de inundação rápida. Por sua vez, o valor do coeficiente de compacidade foi superior à unidade e sendo um índice adimensional varia com a forma e é independe do tamanho da sub-bacia. Nesse sentido, a SBRC apresentou um formato alongado e menor suscetibilidade à ocorrência de inundações e enchentes bruscas.

No que tange à sinuosidade da drenagem, que foi obtida por meio da relação entre o comprimento do riacho Caraúna em linha reta e comprimento do mesmo riacho acompanhando o seu talvegue, apresentou valor de 0,77 . Tal fato indica que os riachos da sub-bacia têm caráter retilíneo e com poucos acúmulos de sedimentos.

A densidade de drenagem encontrada foi de $1,0376 \mathrm{~km} / \mathrm{km}^{2}$,que Villela e Matos (1975) classificam como uma densidade de drenagem moderada, posto que o resultado encontre-se entre os valores de bacias pouco drenadas $\left(0,5 \mathrm{~km} / \mathrm{km}^{2}\right)$ e bacias bem drenadas $\left(3,5 \mathrm{~km} / \mathrm{km}^{2}\right.$ ou mais $)$.

Os dados SRTM permitiram identificar que a declividade na área em estudo apresenta relevo com classes que variam de suave a forte ondulado (Figura 2). A declividade possui relação direta com os processos erosivos atuantes na sub-bacia, por esta razão, o poder público aplicar as políticas de preservação às áreas com maior declividade e suscetibilidade 


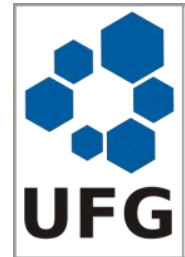

\section{GEOAMBIENTE ON-LINE \\ Revista Eletrônica do Curso de Geografia - UFG/REJ \\ Graduação e Pós-Graduação em Geografia \\ http://revistas.ufg.br/index.php/geoambiente/index \\ Apoio: PRPG/PROAPUPEC \\ Jataí-GO | n 29 | Jul-Dez/2017}

:GEO

亏ัAMBIENTE

ISSN 1679-9860

aos movimentos de massa, como em alguns pontos do alto curso da sub-bacia que apresentaram declividade de 50,49\% (Quadro 2). Contudo, a Sub-Bacia apresenta uma declividade média de $5,44 \%$ e em sua maior parte o revelo é suave a suave ondulado.

Figura 2: Classes de declividade da Sub-Bacia do riacho Caraúna.

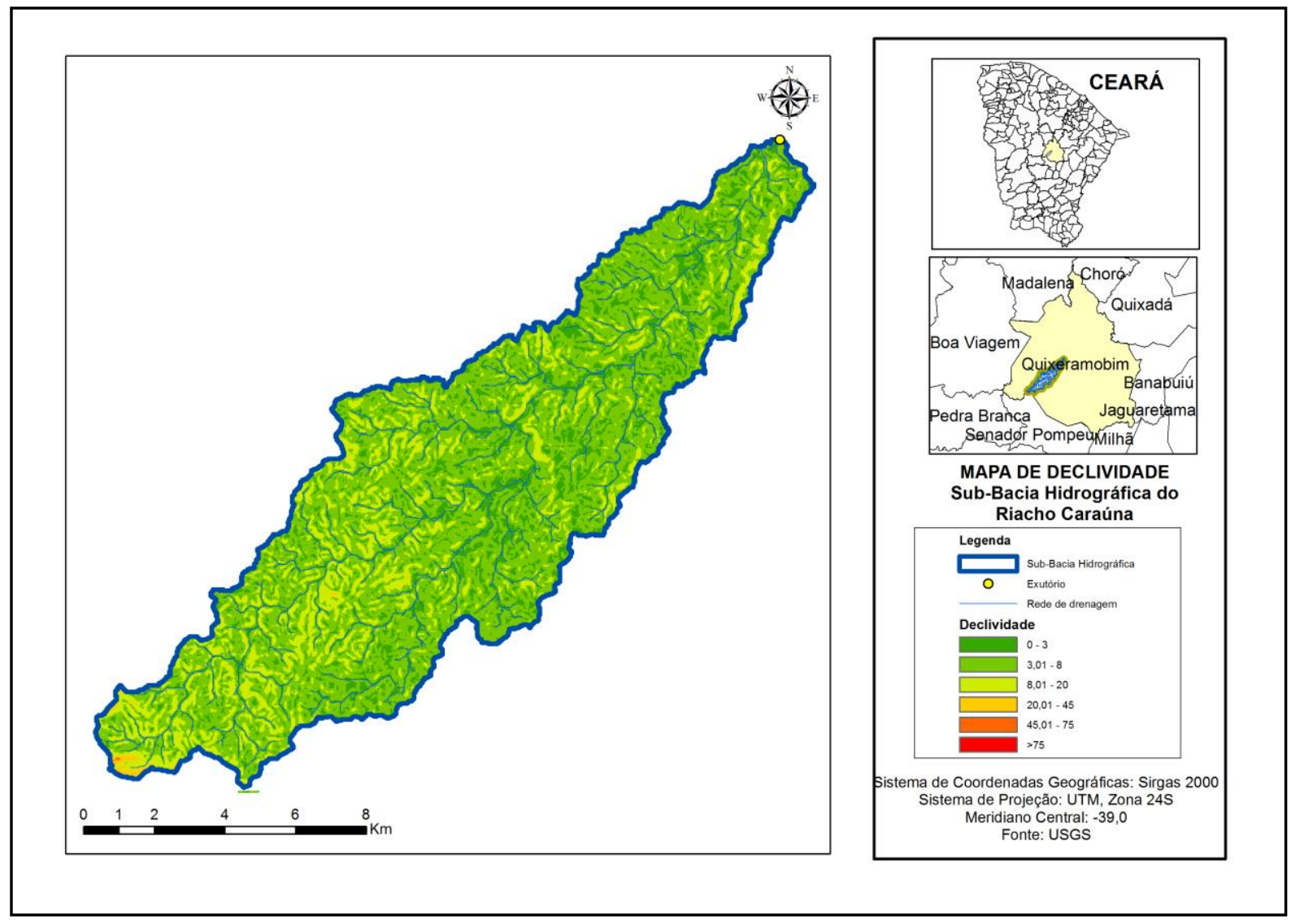

Em relação à altitude da área pode-se constatar que a altitude média é de 269,89 m, a altitude mínima de 202,00 m, a altitude máxima de 464,00 m, enquanto a amplitude altimétrica foi de 262,00 m (Figura 3). Relacionando essas informações com os valores apresentados nos mapas de declividade verificou-se que existe maior concentração da inclinação do terreno no alto e médio curso do riacho Caraúna, sendo que as declividades mínimas e menores altitudes encontram-se no baixo curso. Pode-se, então, inferir que o baixo curso apresenta maior potencial a inundações, devido também a possui relevo plano.

Os resultados obtidos ratificam uma dispersão das águas superficialmente, com poderes erosivos maiores no alto curso, reduzindo gradativamente para o baixo curso, favorecendo a ocorrência de vazão mais lenta no seu exutório. Os dados de declividade e 


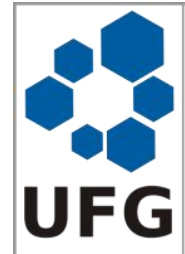

\section{GEOAMBIENTE ON-LINE \\ Revista Eletrônica do Curso de Geografia - UFG/REJ \\ Graduação e Pós-Graduação em Geografia \\ http://revistas.ufg.br/index.php/geoambiente/index \\ Apoio: PRPG/PROAPUPEC}

Jataí-GO | n 29 | Jul-Dez/2017

$\stackrel{\circ}{\underline{\Xi} G E O}$

亡̈AMBIENTE

ISSN 1679-9860

altitude influenciam na precipitação, nas perdas d'água por evaporação, no escoamento superficial e temperatura, conforme Villela e Mattos (1975).

Figura 3: Classes de hipsometriacom as curvas de nível da Sub-Baciado riacho Caraúna.

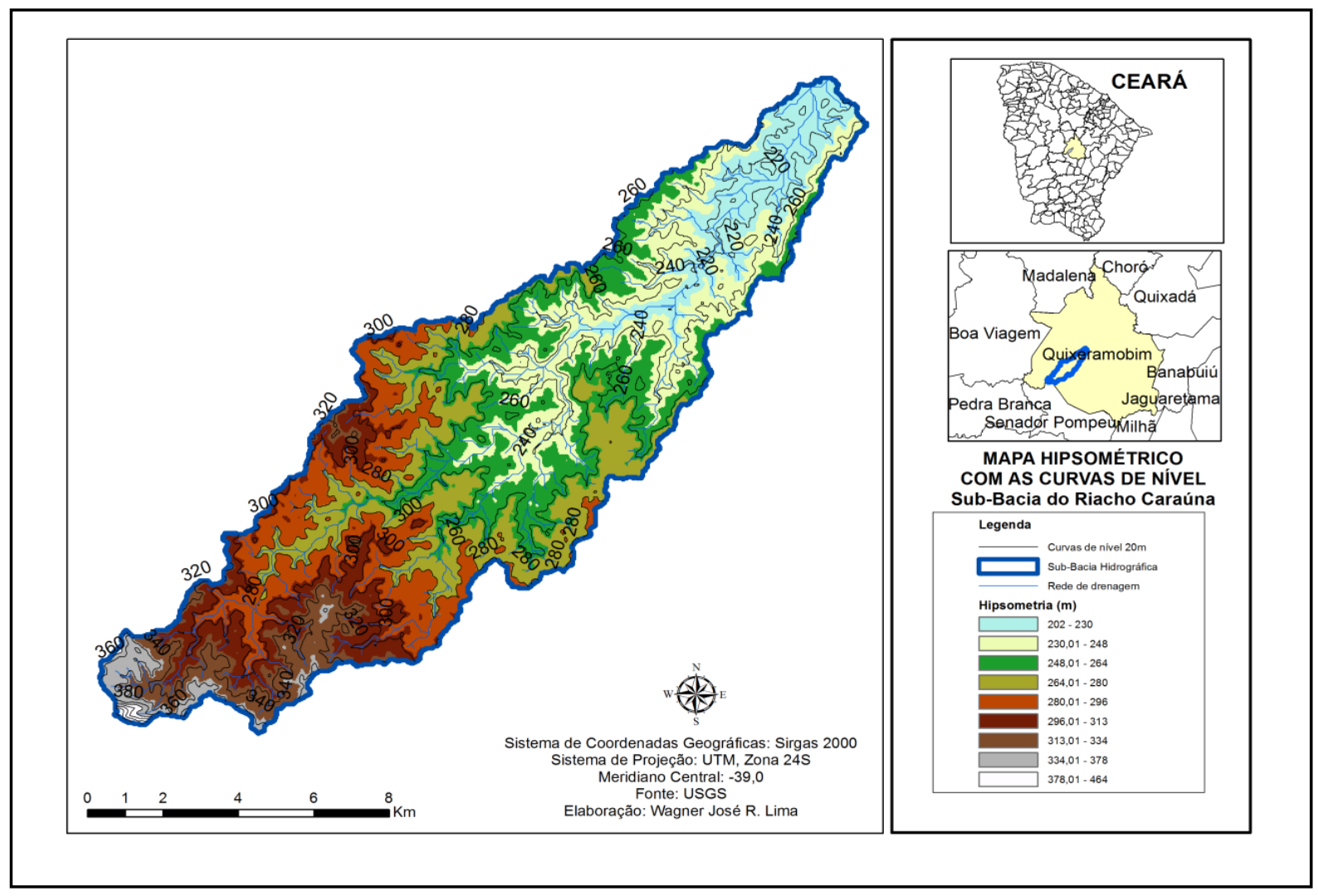

Fonte: USGS (2016).

Diante dos dados expostos, acima, propôs-se a realização de compartimentação da SBRC em baixo, médio e alto curso, para melhor sintetizar os resultados (Figura 4). Essa compartimentação baseou-se em parâmetros hidrográficos como a densidade da rede de drenagem, densidade de riachos e na linha divisora de águas, nas curvas de nível com equidistância de 20 metros e no perfil longitudinal da SBRC. Essa setorização deve servir como ponto de partida para o planejamento territorial, visto que possibilita visualizar de forma completa e, também, por setores, as características morfométricas da Sub-Bacia do riacho Caraúna.

Tomando como base o mapa acima é possível inferir que as áreas com maiores declividades e com maior vulnerabilidade aos processos erosivos situam-se no alto curso. Ao passo que a forma alongada da Sub-bacia representa pouca suscetibilidade a eventos de inundações e enchentes rápidas. 


\begin{tabular}{|c|c|c|}
\hline & $\begin{array}{c}\text { GEOAMBIENTE ON-LINE } \\
\text { Revista Eletrônica do Curso de Geografia - UFG/REJ } \\
\text { Graduação e Pós-Graduação em Geografia } \\
\text { http://revistas.ufg.br/index.php/geoambiente/index } \\
\text { Apoio: PRPG/PROAPUPEC }\end{array}$ & $\begin{array}{l}\mathrm{O} \\
\text { IIENTE }\end{array}$ \\
\hline & Jataí-GO | n $29 \mid$ Jul-Dez/2017 & \\
\hline
\end{tabular}

Figura 4: Proposta de Compartimentação da Sub-Bacia Hidrográfica do riacho Caraúna.

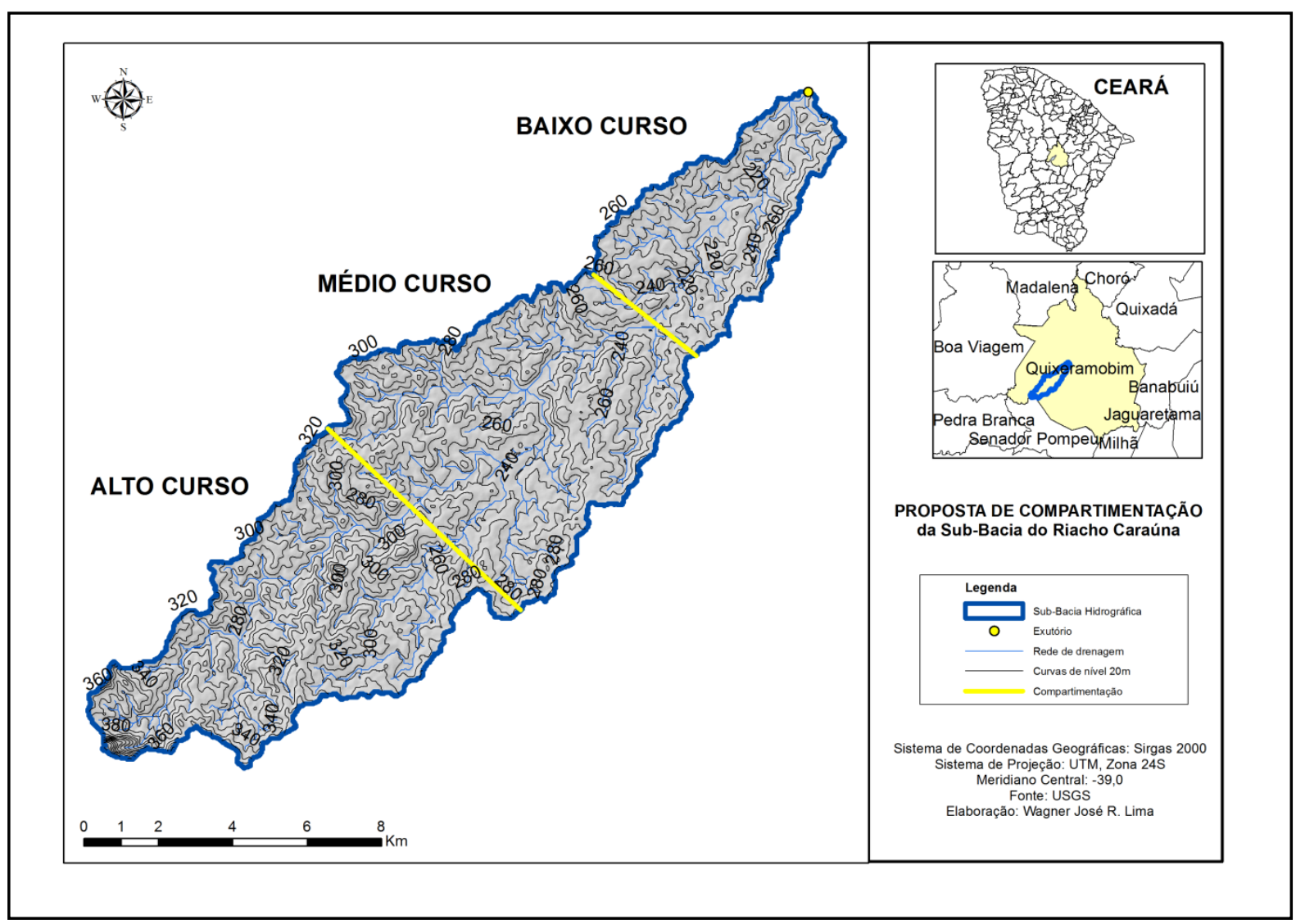

Fonte: USGS (2016).

\section{CONCLUSÕES}

A modelagem do terreno para a Sub-Bacia Hidrográfica do riacho Caraúna (SBRC) resultou num eficiente e confiável delineamento e caracterização morfométrica, juntamente com a rede de drenagem que são utilizadas para os cálculos dos fluxos hidráulicos, transporte e deposição de sedimentos.

A análise dos dados morfométricos evidencia a forma alongada da SBRC com média densidade de drenagem favorecendo na menor possibilidade de ocorrência de enchentes e inundações intensas. No alto curso encontram-se os riachos com maiores declives e áreas mais propensas ao deslizamento de massa, enquanto que no médio e baixo curso predominam as declividades suave e pouco ondulada. 


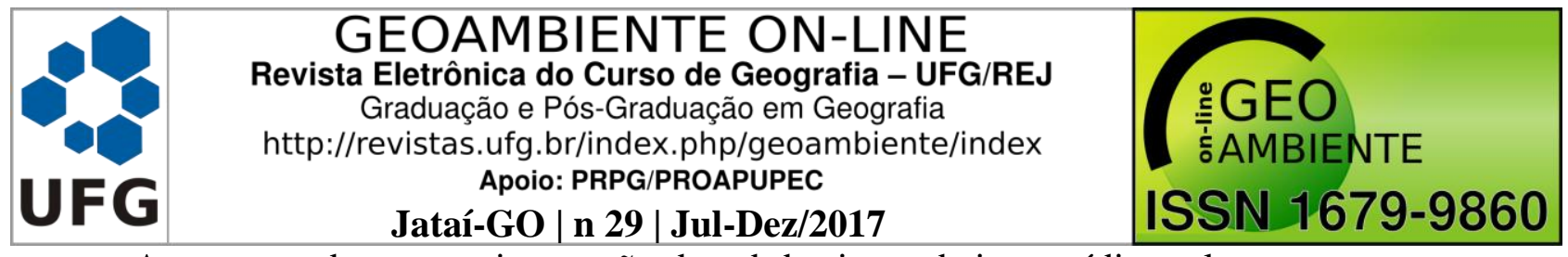

A proposta de compartimentação da sub-bacia em baixo, médio e alto curso, o mapa de declividade, o mapa hipsométrico e o conhecimento da rede de drenagem, podem subsidiar o poder público, através dos seus gestores, no direcionamento dos investimentos em obras hidráulicas como a construção de açudes, passagens molhadas, projetos de irrigação, perfuração de poços tubulares nas planícies aluvionares, construção de áreas de lazer e infraestruturas rurais.

\section{REFERÊNCIAS}

ALVES SOBRINHO, T. Delimitação automática de bacias hidrográficas utilizando dados SRTM. Engenharia Agrícola, Jaboticabal, v.30, n.1, p.46-57, jan./fev. 2010.

ANTONELLI, V.; THOMAZ, E.L. Caracterização do meio físico da bacia do arroio Boa Vista - Guaramiranga-PR. Revista Caminhos da Geografia, v.8, n.21, p.46-58,2007.

ARAÚJO, J.S.; SILVA NETO, A.F.; ARAÚJO, J.S.; GUIMARÃES, C.L. Geotecnologias para a caracterização morfométrica de bacia hidrográfica. 2013. (Apresentação de Trabalho/Simpósio).

CARVALHO, D.F.; MELLO, J.L.P.; SILVA, L.D.B. Bacia Hidrográfica. In:CARVALHO, D.F.; MELLO, J.L.P.; SILVA, L.D.B. Hidrologia, 2007. p.15-24.

CHRISTOFOLETTI, A.Geomorfologia. 2. ed. São Paulo: Edgard Blucher, 1980.

FARIAS, J.F.; SILVA, E.V.; NASCIMENTO, F.R. Caracterização de Sistemas Ambientais como Base Metodológica para o Planejamento Ambiental em Bacias Hidrográficas Semiáridas. Revista Geoamazônia, v. 3, p. 14-27, 2015.

GARCEZ, L.N.; ALVAREZ, G.A. Hidrologia. 2. ed. São Paulo-SP: Editora Edgard Blücher, 1988.

LIMA, R.J.R.; CRISPIM, A.B.; SOUZA, M.J.N.: Mapeamento geomorfológico como subsídio ao planejamento ambiental no município de Quixadá/CE. Revista Geonorte, Edição Especial 4, n.10, n.1, p.555-559, 2014.

MIRANDA, W.A.; MELO, A.A.M.; FIGUEIREDO, F.P.; OLIVEIRA, F.G. A importância do uso do SIG e da análise morfométrica para o plano de manejo em unidades de conservação. In: Simpósio Brasileiro de Sensoriamento Remoto - SBSR, XV, Curitiba - PR, Anais...Curitiba: INPE, 2011, p.1525-1531.

PEREIRA NETO, M.C. Análise areal como subsidio aos estudos integrados da Bacia Hidrográfica do rio Seridó (RN/PB). Revista Equador (UFPI), vol.5, n.4 (Edição Especial 03), p.250-261, 2015. 


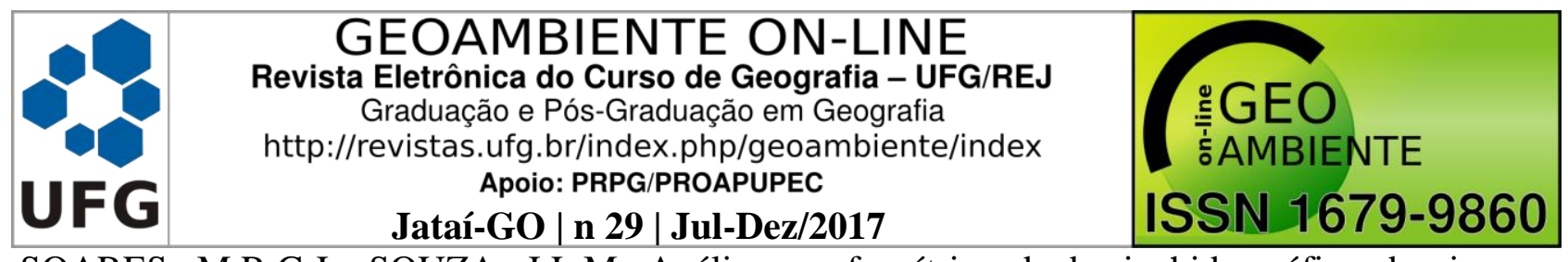

SOARES, M.R.G.J.; SOUZA, J.L.M. Análise morfométrica da bacia hidrográfica do rio pequeno em São José dos Pinhais (PR). Revista: Geografia (Londrina). Londrina, v.21, n.1, p.19-36, 2012.

SOUZA, M.J.N.; MENELEU NETO, J.; SANTOS, J.O.; GONDIM, M.S.; BRITO, É.G. Diagnóstico Geoambiental do Município de Fortaleza: Subsídios ao Macrozoneamento Ambiental e à Revisão do Plano Diretor Participativo - PDPFor. Prefeitura de Fortaleza, Fortaleza, 2009.

STRAHLER, A. N. Hypsometric (area-altitude) - analysis of erosion al topography. Geological Society of America Bulletin, v. 63, n.10, p.1117-1142, 1952.

TONELLO, K.C.; DIAS, H.C.T.; SOUZA, A.L.; ALVARES, C.A.; RIBEIRO, S.; LEITE, F. P. Morfometria da Bacia Hidrográfica da Cachoeira das Pombas, Guanhães - MG. Revista Árvore, v.30, n.5, p.849-857, 2006.

USGS - United States Geological Service (Serviço Geológico dos Estados Unidos). Earth Explorer - Collection - Landsat Archive. Disponívelem:http://earthexplorer.usgs.gov/. Acesso em: 15jan.2015.

VIESSMAN, W. Jr.; HARBAUGH, T.E.; KNAPP, J.W. Introduction to hydrology.New York, Intext Educational, 1972

VILLELA, S.M.; MATTOS, A. Hidrologia aplicada. São Paulo: Ed. McGraw-Hill, 1975.

WHITEHEAD, M.; ROBINSON, P.G. Experimental basin studies: an international and historical perspective of forest impacts.Journal of Hydrology, 15 Maio, 1993.p.217-230. 